\title{
Lo más fresco de la Florida: Pepinos ${ }^{1}$
}

\section{Claudia Peñuela ${ }^{2}$}

\section{Datos nutricionales}

\section{Los pepinos de Florida contienen:}

$\checkmark$ Agua. El agua mantiene el cuerpo hidratado previniendo la retención de agua.

$\checkmark$ Vitamina C. La vitamina C ayuda a curar las cortadas, heridas y a mantener saludables los dientes y encías.

$\checkmark$ Minerales como el fósforo y potasio.

Los pepinos no contienen colesterol, ni sodio y son bajos en calorías.

\section{¿Por qué comprar localmente?}

El Departamento de Agricultura de los Estados Unidos (USDA, por sus siglas en inglés) estima que el promedio de viaje de los productos agrícolas desde su origen hasta los mercados locales del agricultor es de solo $\mathbf{5 0}$ millas, comparado con 2,000 millas hasta los supermercados.

Compre localmente y obtenga estos beneficios:

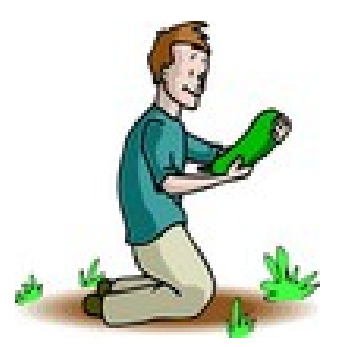

$>\quad$ Frescura y nutrición. Las frutas y verduras cosechadas en su punto tienen mejor sabor y características nutricionales.

$>$ Social/cultural. Ayuda a la comunidad a estar consciente de la importancia de la agricultura.

$>$ Ambiental. Protege los recursos naturales como espacios verdes, fauna, flora, agua, aire y suelos.

$>$ Económico. Promueve la fuerza laboral local.

\section{¿Dónde se cosechan los pepinos de Florida?}

La mayoría de los pepinos de Florida crecen en el centro oeste y sur de Florida. Los agricultores en Florida producen pepinos frescos para el mercado y para procesarlos en encurtidos.

1. Este documento FCS8877-Span, es uno de una serie del Departamento de Ciencias de la Familia, la Juventud y la Comunidad, Servicio de Extensión Cooperativa de la Florida, Instituto de Alimentos y Ciencias Agrícolas, Universidad de la Florida. Fecha primera publicación: agosto 2009. Visite nuestro sitio web EDIS en http://edis.ifas.ufl.edu.

2. Claudia Peñuela, asistente en nutrición-EFNEP, Departamento de Ciencias de la Familia, la Juventud y la Comunidad, Servicio de Extensión Cooperativa, Instituto de Alimentos y Ciencias Agrícolas, Universidad de la Florida, Gainesville, Florida 32611.

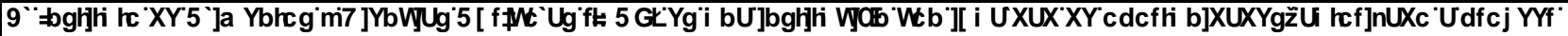
LQYHMDDFLQRinformación educativa y otros servicios, únicamente a los individuos e instituciones que operan sin discriminación DOXQDicon relación a la raza, credo, color, religión, edad, incapacidad, sexo, orientación sexual, estado civil, nacionalidad,

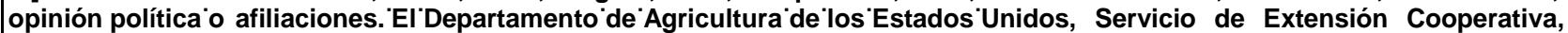
Universidad de la Florida, IFAS, Florida A. $\&$ \&. Programa de Extensión Cooperativa y Juntas de Comisionados del Condado en la cooperación. Millie Ferrer-Chancy, Decana Interina. 


\section{¿Cuándo puede comprar pepinos en Florida?}

Puede comprar pepinos desde octubre hasta junio. ¡Durante nueve meses del año!

\begin{tabular}{|l|l|l|l|l|l|l|l|l|l|l|l|}
\hline ENE & FEB & MAR & ABR & MAY & JUN & JUL & AGO & SEP & OCT & NOV & DIC \\
\hline
\end{tabular}

\section{Seleccione}

$\checkmark$ Pepinos de color verde intenso.

$\checkmark$ Pepinos firmes en toda su longitud, sin puntos blandos.

$\checkmark$ Pepinos bien formados y pesados de acuerdo a su tamaño.

$\checkmark$ Pepinos sin extremos secos.

\section{Pepinos Frescos de la Florida: del mercado a la mesa}

\section{Aderezo de pepino con yogur}

2 tazas de yogur simple, bajo en grasa

2 pepinos grandes, pelados, sin semillas

$1 / 2$ taza de crema ácida sin grasa

1 cucharada de jugo de limón

1 cucharada de eneldo fresco

1 diente de ajo, picado

1 taza de tomates fresadilla (cereza)

1 taza de brócoli

1 taza de zanahorias

Adaptado de: http://www.fruitsandveggiesmatter.gov/downloads/explore recipe cards.pdf

\section{Rinde: 6 porciones Tiempo: 15 minutos}

1. Pele, retire semillas y ralle un pepino. Rebane el otro y guárdelo.

2. Mezcle en un tazón el yogur, pepino rallado, crema ácida, jugo de limón, eneldo y el ajo. Enfríe durante 1 hora.

3. Arregle en una bandeja, los tomates, pepinos, brócoli y zanahorias. Sirva con el aderezo.

*Información nutricional por porción: Calorías: 100 cal; Grasa Total 2g; Sodio $90 \mathrm{mg}$; Carbohidratos Totales 17g; Fibra 2g; Proteína 7g; Vitamina A 70\%; Vitamina C 35\%; Calcio $20 \%$; Hierro 4\%. *El \% del valor diario de vitamina $A$, vitamina C, calcio y hierro está basado en una dieta de 2,000 calorías.

Ensalada de pepinos con vinagre balsámico

Para aderezar

1 cucharada de tomillo finamente picado

2 cucharadas de vinagre balsámico

2 cucharadas de aceite de oliva

2 cucharadas de mostaza Dijon

1 pepino con cáscara, lavado y en rebanadas delgadas Pimienta negra al gusto

\section{Rinde: 2 Porciones}

1. En un recipiente pequeño, añada tomillo, vinagre y aceite de oliva. Caliente a baja temperatura para intensificar los sabores, por más o menos 5 minutos.

2. Remueva del fuego y mezcle bien con la mostaza.

3. En un plato hondo, añada las rebanadas de pepino. Eche el aderezo sobre los pepinos y mezcle para cubrirlo uniformemente.

4. Añada la pimienta negra para dar gusto. Refrigere hasta que este listo para servir.

Información nutricional por porción: Calorías: 160 cal; Grasa Total 14 g; Sodio 184 mg; Carbohidratos Totales 8 g; Fibra $1 \mathrm{~g}$; Proteína $3 \mathrm{~g}$; Potasio 255 mg; Grasa Saturada 2 g; Calcio 37 mg; Grasa Mono insaturada $10 \mathrm{~g}$ 